\title{
LA PARROQUIA DE SANTA EULALIA, CHIHUAHUA
}

\section{Clara Bargellini}

La población de Santa Eulalia (desde 1932 Aquiles Serdán) está situada a $22 \mathrm{kms}$. al sureste de la ciudad de Chihuahua en un territorio accidentado y árido. En esos parajes inhóspitos, se hallaron las vetas de plata que hicieron de San Felipe de Chihuahua y Santa Eulalia una zona minera de primera importancia en el siglo XVIII. ${ }^{1}$ Desde sus inicios entre 1707 y 1709, los dos pueblos se desarrollaron en estrecha relación uno con otro. El poblado del llano, que después de 1718 se llamaría San Felipe, junto al río Chuviscar y cerca de la misión franciscana de San Cristóbal de Nombre de Dios, con su comunidad de indios conchos, fue la cabecera desde su fundación formal, el 12 de octubre de 1709, con el nombre de San Francisco de Cuéllar. Esta fundación es una de las muestras más claras que se tienen de la voluntad de los gobernantes virreinales de establecer poblaciones ordenadas, voluntad también expresada en este caso por la mitad de los 16 pobladores principales de la zona. ${ }^{2}$ La otra mitad quería permanecer cerca de las minas en Santa Eulalia. Al seguirse esta segunda inclinación, se hubiera favorecido el desarrollo de una ciudad parecida a Zacatecas o Guanajuato, con calles y callejones según los accidentes del terreno (figs. 1 y 2). Precisamente para evitar esto el gobernador de la Nueva Vizcaya, Antonio Deza y Ulloa, decidió a favor del llano,. donde se pudo trazar una población de calles rectas y predios regulares, y así quedó el mineral de Santa Eulalia subordinado a San Francisco de Cuéllar.

No fue una decisión libre de conflictos. La prueba está en que desde

1 La bibliografía básica para la historia del lugar es: Francisco R. Almada, Diccionario de historia, geografía y biografía chihuahuenses, 2â. ed., Chihuahua, Universidad Autónoma de Chihuahua, 1968; Peter Gerhard, The North Frontier of New Spain, Princeton, Princeton University Press, 1982; Phillip L. Hadley, Minería y sociedad en el centro minera de Santa Eulalia, México, FCE, 1979; Clara Bargellini, La Catedral de Chihuahua, México, UNAM, 1984, especialmente pp. 63-65, para la historia artística.

2 Las ordenanzas respecto a poblaciones están publicadas en "Fundación de pueblos en el siglo XVI", Boletín del Archivo General de la Nación, tomo 6 (3), 1935, pp. 321-360. Los textos de las opiniones de los vecinos y del gobernador se encuentran en Francisco R. Almada, Documentación sobre la ciudad de Chihuahua, Chihuahua, 1942. De ahí vienen las citas que siguen en el texto. 
el primer momento el gobernador Deza y Ulloa consideró necesario decretar que en Santa Eulalia "en lo adelante ninguna persona de ningún estado, calidad o condición que sea, puede labrar ni labre casa, jacal, ni otra oficina de habitación, pena de 200 pesos, aplicados para la fábrica de la iglesia de la cabecera". Siendo la iglesia parroquial el edificio que señalaba la importancia de un poblado, es indicativo que Deza y Ulloa ordenara que en Santa Eulalia sólo se construyera "una capilla comoda..., sin pasar a exceso de la fábrica". La capilla construida en Santa Eulalia era de 30 varas de largo, 8 de ancho y 8 de alto, con "techo de madera", y su sacristía medía $8 \times 5 \times 4$ varas, según un inventario de $1760 .^{3}$

Sabemos además, por dos documentos de la visita del obispo Benito Crespo de mayo de 1730, que tenía un retablo mayor hecho en la Ciudad de México y pagado por Francisco González Ramírez, comisario del Santo Oficio (anexo 1). ${ }^{4}$ Crespo lo dedicó en su visita. ${ }^{5}$ Este retablo, de tres cuerpos, que tenía una imagen de Santa Eulalia, debe haber sido salomónico, dada la fecha de su construcción, y es probable que sería el mismo que se describió años más tarde en el inventario de 1760 (anexo 2). La talla de la santa, muy maltratada, probablemente es la que hace unos años estaba en la sacristía y ahora se custodia en la capilla de Guadalupe a poca distancia de la parroquia. En 1760 , estaba todavía en el altar mayor, del lado del evangelio, una imagen de Nuestra Señora de la Merced, para la cual Crespo había dejado órdenes de que se construyera una capilla propia en la misma parroquia. ${ }^{6}$ Parece, por lo tanto, que ésta no se había hecho. La preocupación que externa Crespo respecto a la "capacidad" de la iglesia sugiere que Santa Eulalia prosperaba. El obispo confirmó 312 personas "con 25 indios julimes" en el real. ${ }^{7}$ Nombró a Francisco González Ramírez "mayordomo perpetuo" de la cofradía de Santa Eulalia que estableció en su visita; los estatutos se basarían en los de la cofradía de la Virgen del Rosario en San Felipe. Esta cofradía de Santa Eulalia, en efecto, es una de las registradas en el mineral en sep-

3 Archivo de la Catedral de Durango (en adelante ACD), Libro $X X X V$, f. $180 \mathrm{v}$.

4 El documento del anexo 1; del ACD, forma parte de otro, ya publicado, sobre San Felipe de Chihuahua: Bargellini, op. cit., p. 83. El segundo documento se encuentra en el Archivo de la Catedral de Chihuahua, sin clasificar. Se cita parcialmente en Ibid., p. 63. Aquí se proporcionan más detalles.

5 ACD, Libro XLV, f. 52.

6 A esta capilla "que se ha de labrar", Crespo aplicó el legado del testamento de un Fernando Bustamante: Ibid., f. 44.

7 Ibid, f, 51 v. En Chihuahua fueron 1,411 los confirmados. 
tiembre de 1742, durante la visita del obispo Martín de Elizacochea, junto con las del Santísimo, del Rosario, de las Ánimas, del Carmen, de la Fábrica y una Hermandad de Dolores. ${ }^{8}$

Hasta aquí lo que se conoce de la primera iglesia de Santa Eulalia. Ahora el hallazgo de un importante grupo de documentos (anexos 3-6) hace posible la reconstrucción más precisa de la historia posterior de este templo y arroja luz sobre el modo de proceder de vecinos, clérigos y maestros en aquella época. ${ }^{9}$ Los nuevos descubrimientos se complementan en este ensayo con algunas otras noticias provenientes del Archivo de la Catedral de Durango.

En 1755, los vecinos de Santa Eulalia se pusieron de acuerdo para reparar el techo de su ya vieja parroquia y remozarla con una nueva capilla mayor y un crucero con cúpula. Al disponer de más fondos, se completaría esta nueva construcción para llegar a tener un templo abovedado de 50 varas de largo. Los documentos de los anexos 3,4 y 5 proporcionan todos los detalles y me limitaré, por lo tanto, a resumir to que se refiere al proceso de construcción. Se hicieron las diligencias necesarias con el obispo Sánchez de Tagle, quien nombró al teniente de corregidor, Juan Josê Barrandegui, como administrador de la obra, la cual iba a costearse con el fondo establecido en 1727 para la construcción de la iglesia de Chihuahua. ${ }^{10} \mathrm{~A}$ este monto contribuían los mineros y los comerciantes según la cantidad de plata que se sacaba de las minas, más se le había añadido lo recaudado de un impuesto sobre la venta de carnero. Faltando poco para la terminación de la gran iglesia de tres naves de la cabecera, se pensó en que se pudiera rehacer la de Santa Eulalia, y contribuir, además, a la construcción de la iglesia de los jesuitas en San Felipe, como consta en la carta escrita por Barrandegui (anexo 4).

En su comunicación al obispo (anexo 3), el cura de San Felipe no proporciona el nombre del "maestro de alarife" quien dio su opinión respecto a la obra de Santa Eulalia, pero es muy probable que haya sido uno de los dos maestros que estaban contratados en la parroquia de Chihuahua en 1755: Nicolás Núñez y Cristóbal de Villar, éste último con el título de "Maestro Alarife"." Poco después apareció en la escena

8 ACD, Libro XLVIII, f. 143 v.

${ }^{9}$ Los documentos fueron encontrados por la Señora Mary Taylor, a quien agradezco la gentileza de haberme enviado copias fotostáticas. Supe de ellos por el padre Manuel Acosta, del Archivo de la Catedral de Chihuahua, y por el arquitecto Gastón Fourzán, a quienes también expreso mi reconocimiento.

10 Bargellini, op. cit., p. 23.

11 Ibid., p 28. En 1755 Villar trazó el atrio de la iglesia de Chihuahua. 
Bernardo del Carpio. Hasta ahora, el maestro Bernardo del Carpio sólo era conocido por el contrato para la terminación de las torres gemelas de la parroquia de Chihuahua en diciembre de $1757 .{ }^{12}$ Aquí se añaden sus dibujos de la planta y la fachada con torre de la parroquia de Santa Eulalia (figs. 3 y 4), junto con el presupuesto que hizo de la obra y de una presa para el mismo poblado en 1758 (anexo 6).

Ninguno de los nuevos documentos menciona los orígenes y los antecedentes de Bernardo del Carpio. Sin embargo, su presupuesto y los dibujos de 1758 no sólo informan sobre precios de materiales y mano de obra y demuestran cómo iba a ser la nueva iglesia; también dan testimonio de que no se había avanzado mucho en el proyecto de 1755 . Un pequeño texto que acompaña el croquis de la fachada dice:

La Yglesia que antes se planteó, segun se persive de los zimientos abiertos, fue de zincuenta varas de largo, y diez de ancho, y despues haviendo suvido a el Real los que fuimos nombrados a regular su costo, nos dijeron que, a razon de las muchas calamidades que por falta de agua esperimentaban, nezesittaban mas de una pressa que de la Yglesia, que haziendosela se contentarian despues con una de 40 varas de largo, y ocho de ancho que es el mismo de la que tienen añadiendole crucero como aqui se figura, con lo que se tasso una y otra obra por el Maestro Carpio como consta adelante.

En 1760 todavía no se había progresado en la construcción del templo. Tocó en ese año el enérgico obispo Pedro Tamarón dar otro paso. "Estando en mi visita, bendije la primera piedra a la fábrica de nueva parroquia, grande, muy capaz para la mucha gente que suele concurrir, y tengo noticias de estar muy adelantada", escribió en $1765 .{ }^{13} \mathrm{El}$ obispo constató la existencia en Santa Eulalia de las cofradías de Dolores, del Rosario, del Santísimo, de las Ánimas, de Santa Eulalia, de la Merced y del Carmen, ${ }^{14}$ y mandó hacer el inventario de la parroquia ya mencionado (anexo 2). Uno de los libros con apuntes de la visita de Tamarón ${ }^{15}$ proporciona datos más precisos y un poco menos optimistas que los que registró en la Demostración. Aprendemos que Tamarón estuvo en Santa

12 lbid., pp. 84-87.

13 Pedro Tamarón, Demostración del vastisimo obispado de Nueva Vizcaya, 1765, México, Porrúa, 1937, p. 54.

14 ACD, Libro $X X X V$, ff. $180-190$ v. Hoy están el altar del Santísimo y una Virgen de Dolores en los cruceros y la Virgen del Carmen en el primer tramo de la nave lateral.

15 ACD, Libro LIII, ff. 136-137. 
Eulalia desde el 15 hasta el 18 de septiembre de 1760. El primer día hubo celebraciones; entre ellas, en un "altar fuera en el cementerio se representó una arrogante loa". Después el obispo "salió a reconocer el lugar destinado a la fábrica de la iglesia". Al día siguiente tuvo una reunión con los vecinos quienes no estaban todavía decididos a emprender la construcción, pero logró convencerlos y el día después fue cuando "bendijo el lugar y puso la primera piedra" de una iglesia que iba a medir $50 \times$ 10 varas. Es decir, insistió en el proyecto de 1755.

En este punto terminan los documentos y debemos dirigirnos al edificio mismo para tratar de entender qué sucedió. Para iniciar la construcción, según el libro de visita, Juan José Barrandagui tenía 6,422 pesos. Una simple comparación de esta cifra con el presupuesto de más de 27,000 pesos para una iglesia de $40 \times 8$ varas del arquitecto Del Carpio deja de manifiesto que el optimismo de Tamarón se había alimentado más de sus anhelos que del conocimiento de la situación de Santa Eulalia. Los vecinos, más apegados a su realidad, quisieron la presa y recayeron en el proyecto de la iglesia de $40 \times 8$ varas, no de $50 \times 10$, como podemos constatar por la planta actual (fig. 5). Al comparar esta planta con la de 1758 (fig. 4), se puede ver que en buena parte se siguieron las ideas y las dimensiones indicadas por Bernardo del Carpio. Las dos plantas se parecen en todo, menos en la añadidura de una nave lateral y en una ligera alteración de las medidas de la antesacristía. De hecho, por las marcas en las canteras del ábside, crucero y cúpula, que encuentran algunas correspondencias en la iglesia mayor de San Felipe, ${ }^{16}$ se puede pensar que esa parte del edificio se levantó primero, como había sido planeado desde 1755. También todas las tallas en cantera de la sacristía, antesacristía, portadas e interior de la iglesia (fig. 6-10) son comparables a las obras chihuahuenses de hacia $1750-1760$, especialmente a la portada de la capilla del Rosario de la parroquia y a lo que queda de la portada mayor de la iglesia de Loreto. ${ }^{17}$ Incluso se llegó a hacer el cubo de la torre, dentro del cual está el bautisterio con bóveda de arista.

Pero, ¿cómo explicar la nave lateral? No está en el plano de 1758; sin embargo, hay que reconocer, como acabo de señalar, que la cantera labrada de las claves de sus arcos interiores y de su portada corresponde a mediados del siglo XVIII. El diseño de la portada lateral hasta tiene rasgos en común con el dibujo de Bernardo del Carpio para la fachada

16 Bargellini, op. cit., p. 66.

17 Ibid., p. 64, con ilustraciones. 
de la iglesia, por lo menos en cuanto a sus elementos arquitectónicos principales, si no en sus detalles decorativos, y los arbotantes-gárgolas recuerdan los de la parroquia de Chihuahua. Todo esto lleva a pensar que la nave lateral fue añadida al proyecto de Bernardo del Carpio en tiempos no muy alejados de 1758 . Es obvio que se quería una iglesia de tres naves, sólo que la tercera nunca se pudo construir. De hecho, los datos de población sugieren que en la segunda mitad del siglo XVIII Santa Eulalia gozó de cierta pequeña ventaja respecto a la cabecera. ${ }^{18}$ Los vecinos y las autoridades eclesiásticas habrán considerado que el crecimiento de Santa Eulalia merecía una parroquia de tres naves, como tenían las poblaciones más importantes de la región centro-norte en esa época.

Las esculturas y decoraciones en cantera deben haberse preparado alrededor de 1760, cuando se emprendió la obra del nuevo templo, y fueron integradas a la arquitectura posteriormente. El desfase cronológico entre la ejecución de las tallas y su utilización ofrece una explicación para la presencia de San Luis Gonzaga en la clave del vano de la portada lateral (fig. 8), figura a la que hubiera correspondido estar más bien en la iglesia de los jesuitas, la cual, como se señaló antes, también estaba en obra hacia 1750-1760. Se habría tallado la pieza y, al no necesitarla en la Vi1la de San Felipe, tal vez después del destierro de los jesuitas en 1767, fue llevada a Santa Eulalia. La existencia de la hornacina de un nicho, nunca utilizada (fig. 10), confirma la impresión de una obra integrada por elementos heterogéneos, un poco a la buena, cuando y como se pudo. Más aún, me pregunto si esta portada no sería, de hecho, la lateral de la iglesia de los jesuitas, menos el marco y algunos detalles del remate. Se parece en su estructura general y, especialmente, en el nicho superior, aunque las viejas fotografías, que son el único testimonio de las portadas de la iglesia de Loreto en la Villa de San Felipe, no permiten juzgar con certeza. ${ }^{19}$ En tal caso, la portada se habría llevado a Santa Eulalia después de hacia 1880, cuando fue derrumbada la iglesia de los jesuitas. De todos modos, la nave lateral de Santa Eulalia sería una construcción del siglo XVIII. Una de las campanas que actualmente está en la torre de Santa Eulalia es de 1778 y podría ser evidencia de que para entonces estaba terminada la nave lateral con el cubo de la torre, por lo

18 Gerhard, op. cit., p. 200.

19 Véase Marco Díaz, La arquitectura de los jesuitas en Nueva España, México, UNAM, 1982, p. 207, y Bargellini, op. cit., pp. 60-62. Tuve oportunidad de examinar la fotografía en el Centro Cultural de Chihuahua. 
menos. ${ }^{20}$ El retablo mayor anástilo que hoy puede apreciarse en Santa Eulalia (fig. 11), a pesar de las muchas alteraciones que ha sufrido, ${ }^{21}$ también debe de ser de esa época.

Sabemos que hacia la última década del siglo hubo un nuevo periodo de prosperidad en San Felipe y Santa Eulalia. ${ }^{22}$ Fue entonces cuando se pudo terminar la fachada de la parroquia. Esta fue obra del maestro arquitecto Nicolás Morín, de Durango, quien hizo el retablo principal y restauró la portada mayor de la parroquia de Chihuahua. ${ }^{23} \mathrm{El}$ presupuesto que Morín presentó en 1790 para "la obra material" de Santa Eulalia fue de 21,018 pesos. En la primera mitad del siglo XIX, se añadieron los dos retablos de cantera, los cuales se parecen a unos de 1826 de la parroquia de Chihuahua. ${ }^{24}$ Uno corresponde al altar del Santísimo (fig. 12), donde ahora se conserva una bella talla de la Virgen de Loreto proveniente, con toda probabilidad, de la iglesia de los jesuitas de la villa, y el otro para la Virgen de Guadalupe al fondo de la nave lateral (fig. 13). La torre actual, junto al cubo de la original, tiene inscrita la fecha "Mayo 1854" en su base y debe de haberse terminado en ese año, aunque no hay que descartar la posibilidad de que la haya iniciado el arquitecto Nicolás Morín, o sus sucesores inmediatos, para dejarle más amplitud al frontón de la fachada. También la campana grande, de nombre Eulalia Guadalupe de Jesús, ostenta la fecha de 1854.

Estas breves líneas y los documentos anexos aclaran la historia de la iglesia de Santa Eulalia. Sólo quedan por añadir algunas consideraciones respecto a Bernardo del Carpio y la presa de agua, su otra obra en el real de minas, cuyo costo se especifica en el presupuesto de 1758 (anexo 6). Esta es una de las pocas obras civiles coloniales que se conservan en la zona, aunque ahora está arruinada y en desuso. En un codo del arroyo que pasa por el poblado, se pueden ver los restos de unos muros de contención, un vertedero y de la compuerta, con ocho de las " 24 piedras de medida" mencionadas en el presupuesto. Se aprecian con claridad los lugares para ocho más en las paredes verticales y se pueden suponer que las ocho restantes se distribuían abajo y arriba.

20 No es la campana más antigua. Esta es una chica con el nombre de Señora de Dolores con fecha de 1719.

21 Se conserva todavía la tela del espacio superior izquierdo, con la representación de Jesús en el Getsémani. El sacristán recuerda haber visto, en la sacristía, hace unos 40 años, las dos telas que corresponderían a la zona inferior.

22 Gerhard, loc, cit.

23 Bargellini, op. cit., pp. 71-72, con ilustraciones; el presupuesto, p. 89.

24 Ibid., p. 79, fig. 67. 
Por lo que toca el trabajo de Bernardo del Carpio en la iglesia, llama la atención que el dibujo de la torre de Santa Eulalia, que nunca fue construida, recuerda la torre del templo de San Francisco en Chihuahua (fig. 14) . No sería extraño, por lo tanto, que el maestro haya sido el autor también de esa obra. Es muy posible, además, que se haya encargado de la iglesia de los jesuitas, por la notoria escasez de arquitectos en la región y por ser ésta una obra a la que contribuían los fondos parroquiales.

Poco podemos decir de los espacios de Bernardo del Carpio, porque la parroquia de Santa Eulalia no es más que una copia en menor escala de la de Chihuahua. En cuanto a su estilo ornamental, es notable la sobriedad del dibujo de la fachada y torre de Santa Eulalia. Deja los elementos arquitectónicos escuetos y con poquísimos adornos. Contrasta esta simplicidad de diseño con las portadas mencionadas antes, que no se quedaron en proyecto, sino que fueron talladas en esos años, como la misma portada lateral de Santa Eulalia. Posiblemente esta simplicidad de Bernardo del Carpio no haya sido más que el resultado de la prisa o conveniencia en la presentación. Sin estudios sobre los dibujos arquitectónicos novohispanos de la época, es imposible pronunciarse definitivamente. Puede ser, sin embargo, que en ella ya haya un indicio de una depuración de origen neoclásico que empieza a aparecer en la Nueva España mucho antes del establecimiento de la Academia de San Carlos. Sugiere, por lo menos, que arquitectos y canteros seguían senderos de desarrollo distintos.

\section{ANEXOS}

1. Auto del obispo Benito Crespo, 7 de mayo de $1730, A C D, L i b r o ~ X L V$, ff. $55.55 \mathrm{v}$.

En despacho aparte mando su Ilma que de los 900 pesos que se deven a dicha fábrica que se avian de aver aplicado para el retablo de dicha Yglesia, por haverse ya echo este sin dicha cantidad a devosion del Br. Juan Francisco González Ramirez, los aplicaba para la ovra y fabrica de una capilla que en la misma iglesia parroquial se ha de azer a Nuestra Señora de la Merced, ${ }^{1}$ cuya providencia se dió assi para que haviendo dicha capilla aya mas capasidad en la referida Yglesia parroquial que redunda utilidad a los fieles como, porque colocandose dicho retablo en el altar mayor no tiene lugar dicha soberana Señora por dever estar en el primer nicho la gloriosisima Virgen y Martir Santa Olaya, ya como patrona unica de dicho Real y Yglesia. Y en interim se

1 El documento aquí dice "del Carmen", pero es evidentemente un error, dado que más adelante, y en todos los demás documentos, se habla de la Merced. 
DOI: http://dx.doi.org/10.22201/iie.18703062e.1989.60.1530

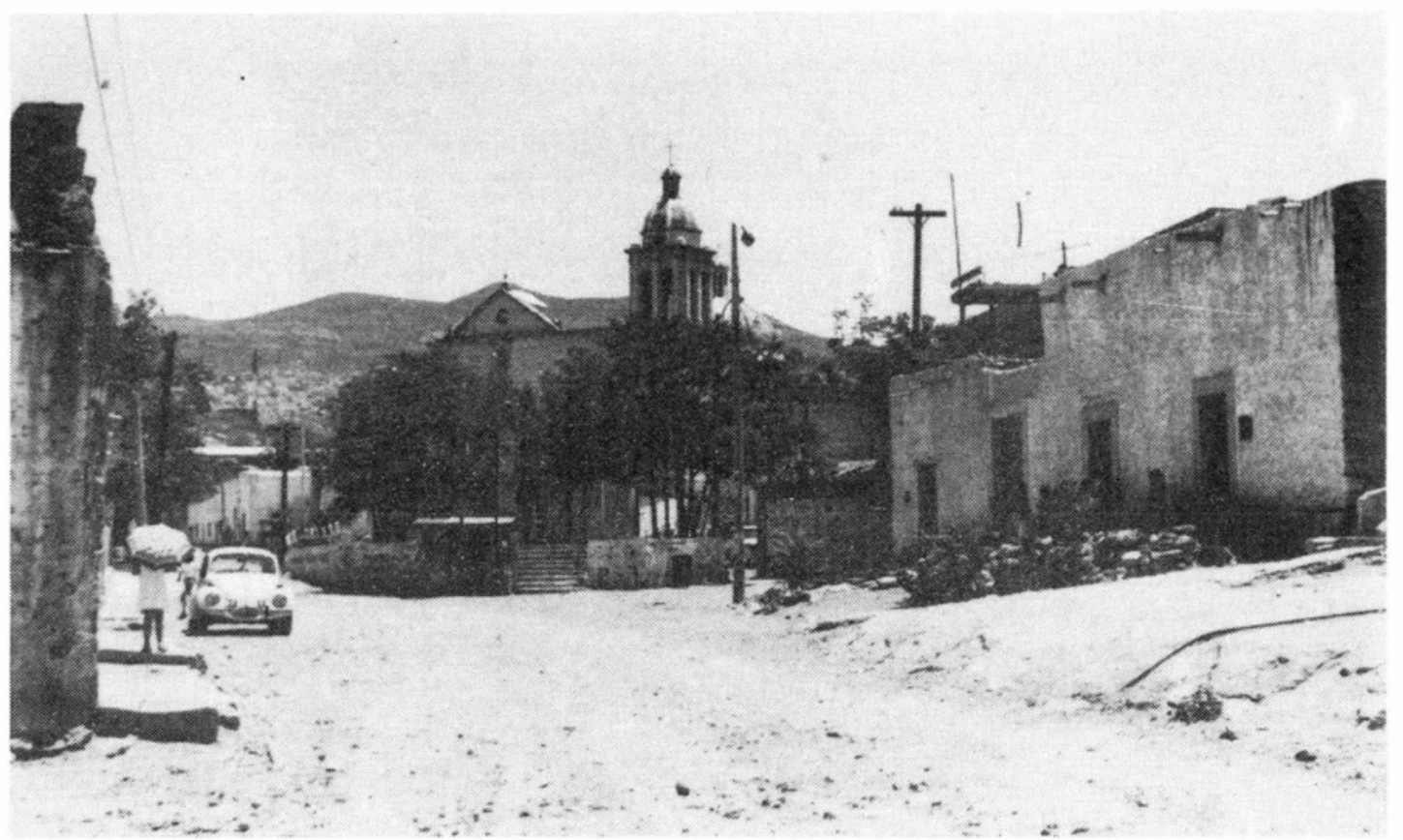

1. Santa Eulalia. Vista general de la parroquia y de la calle principal desde el oeste.

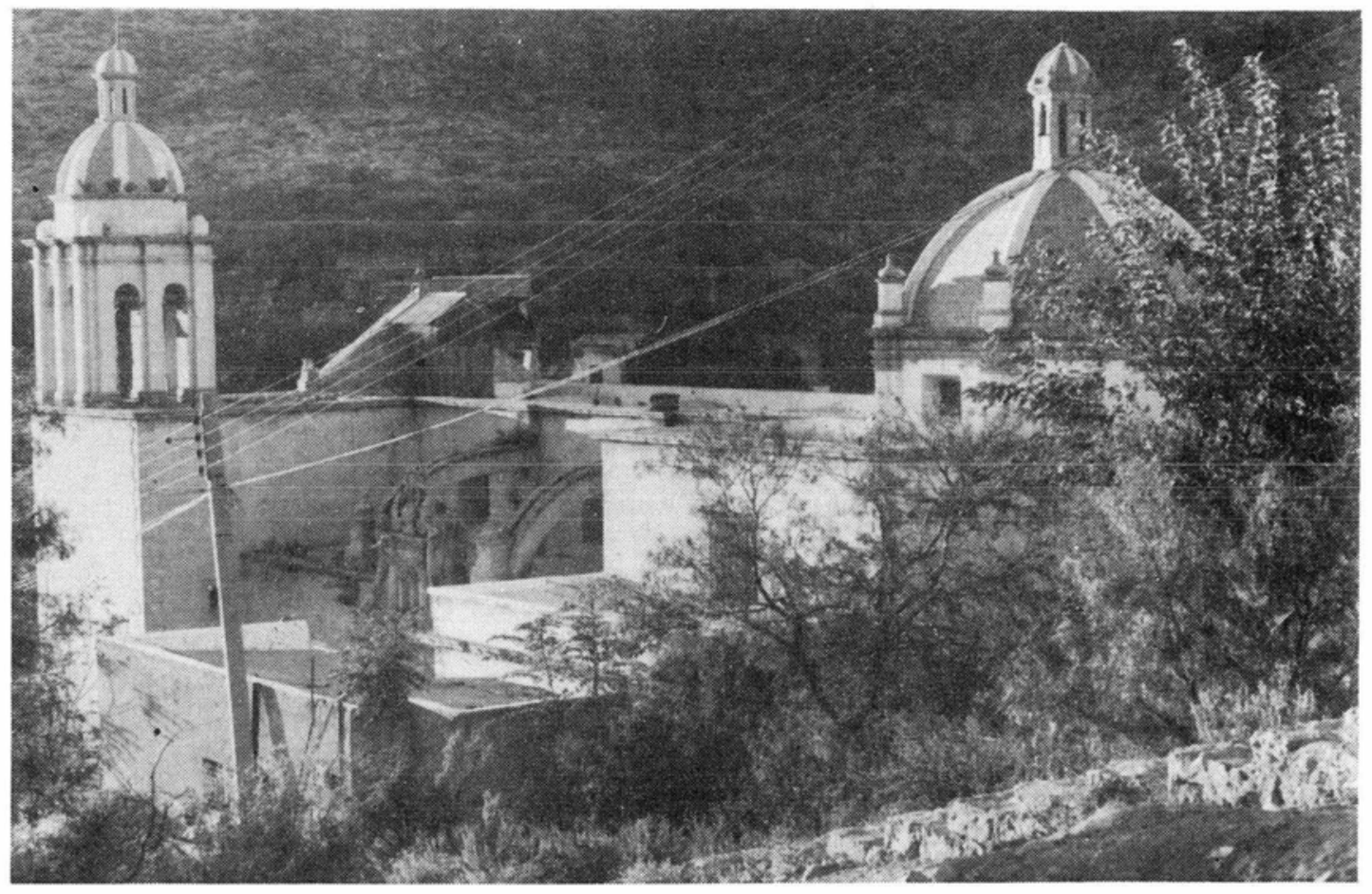

2. Santa Eulalia. Vista general de la parroquia desde el sureste. 


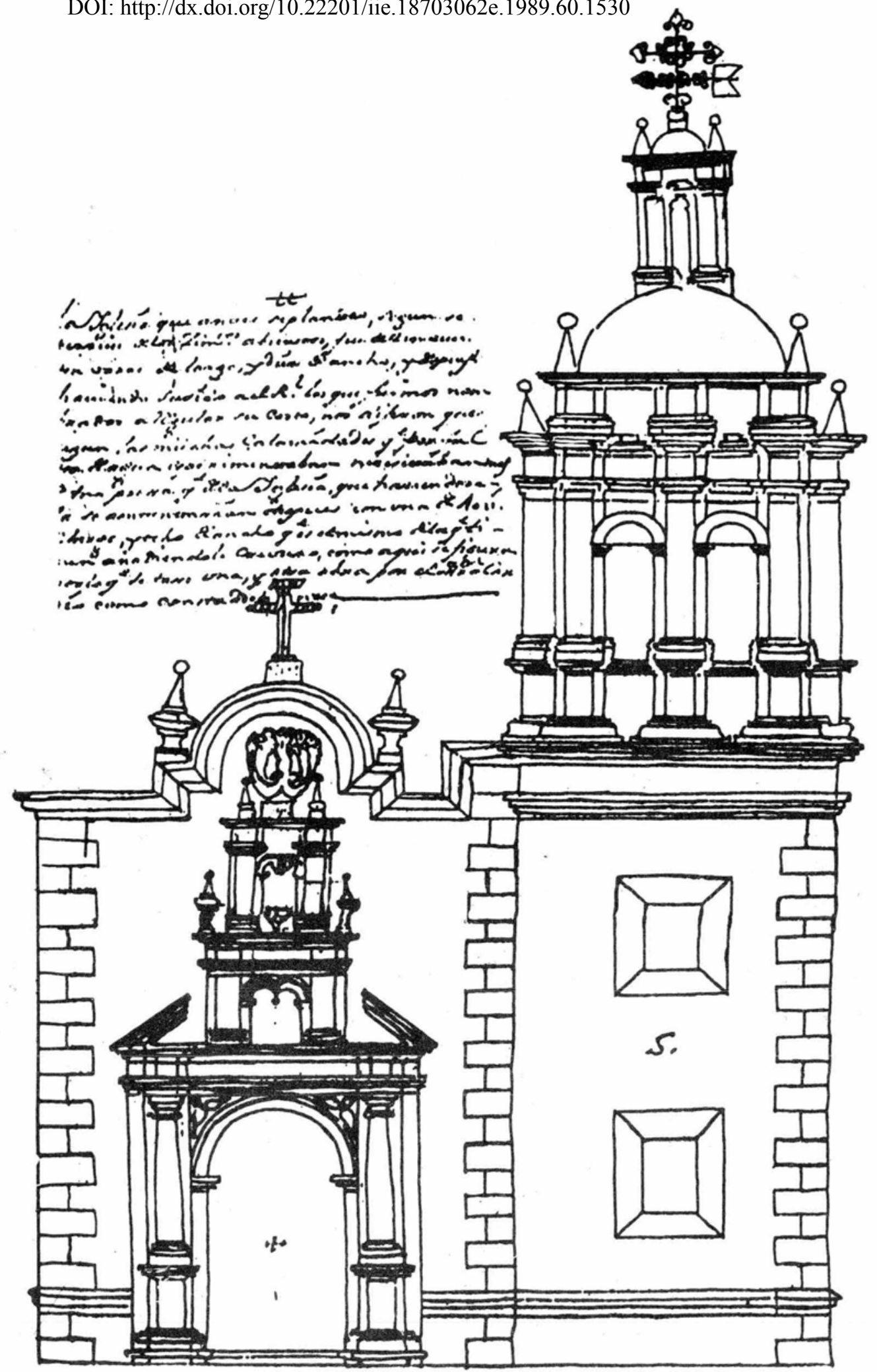

3. Bernardo del Carpio. Dibujo para la fachada de la parroquia de Santa Eulalia. 1758. 
DOI: http://dx.doi.org/10.22201/iie.18703062e.1989.60.1530

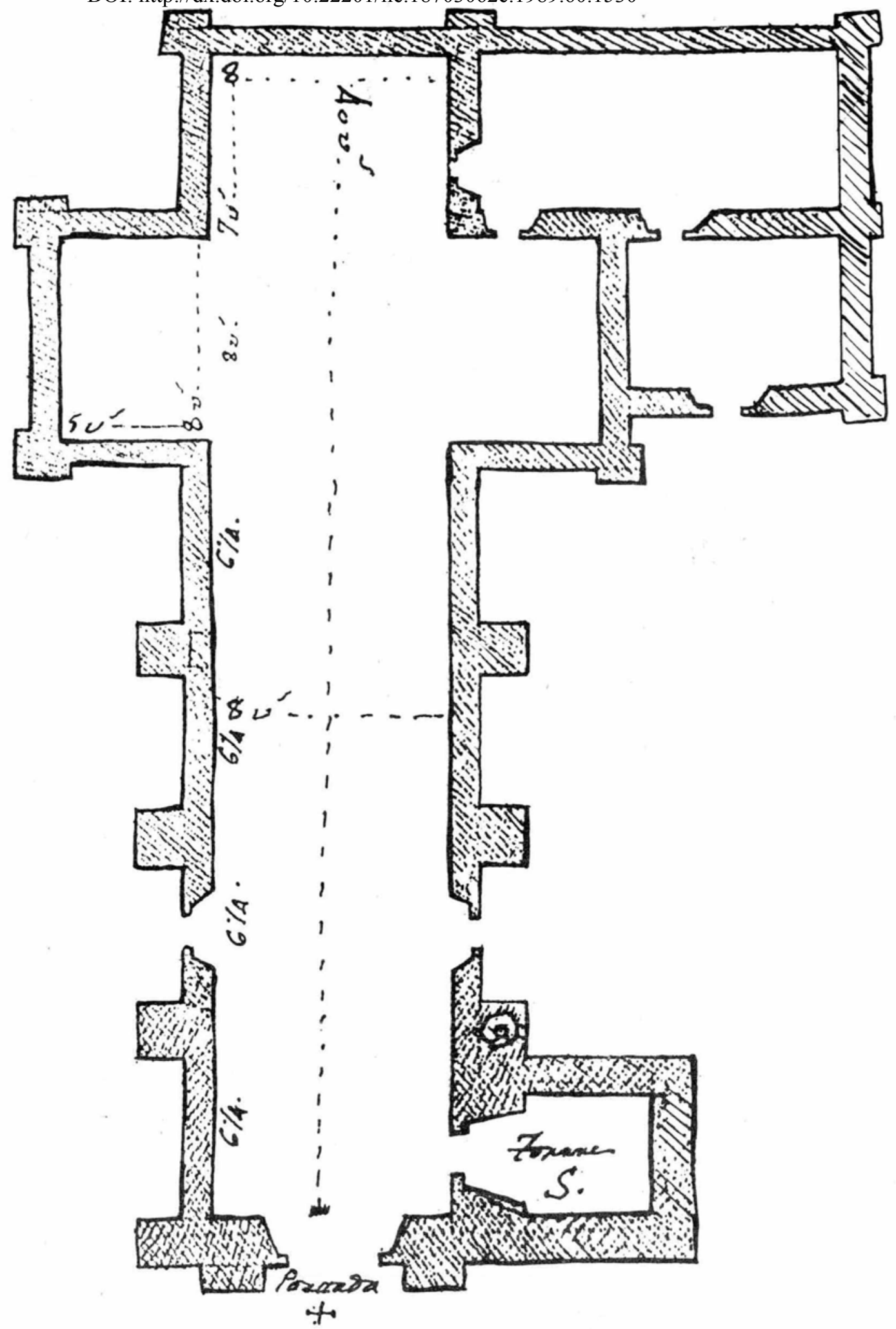

4. Bernardo del Carpio. Planta para la parroquia de Santa Eulalia. 1758. 


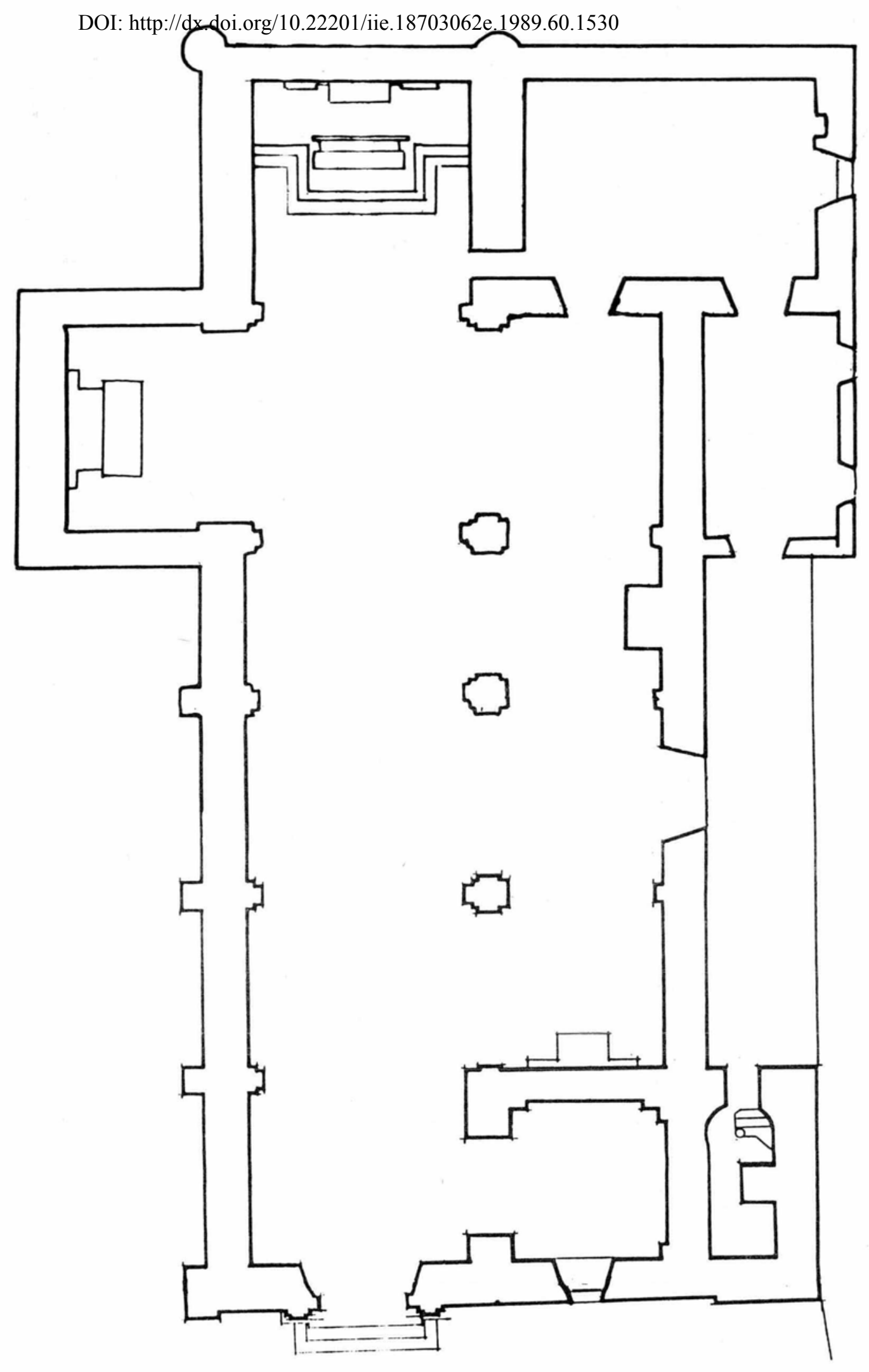

5. Planta actual de la parroquia de Santa Eulalia. 
DOI: http://dx.doi.org/10.22201/iie.18703062e.1989.60.1530

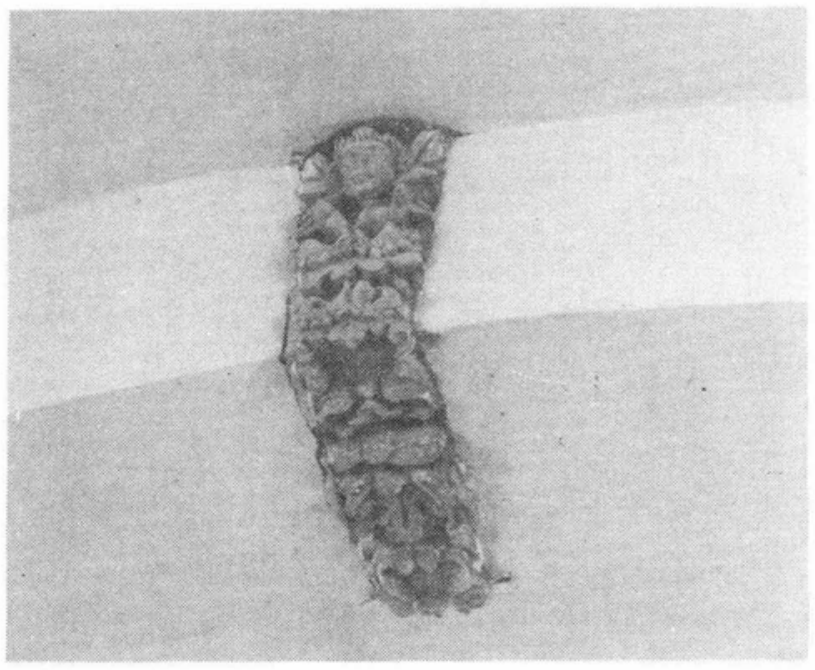

6. Parroquia de Santa Eulalia. Clave de un arco de la nave.

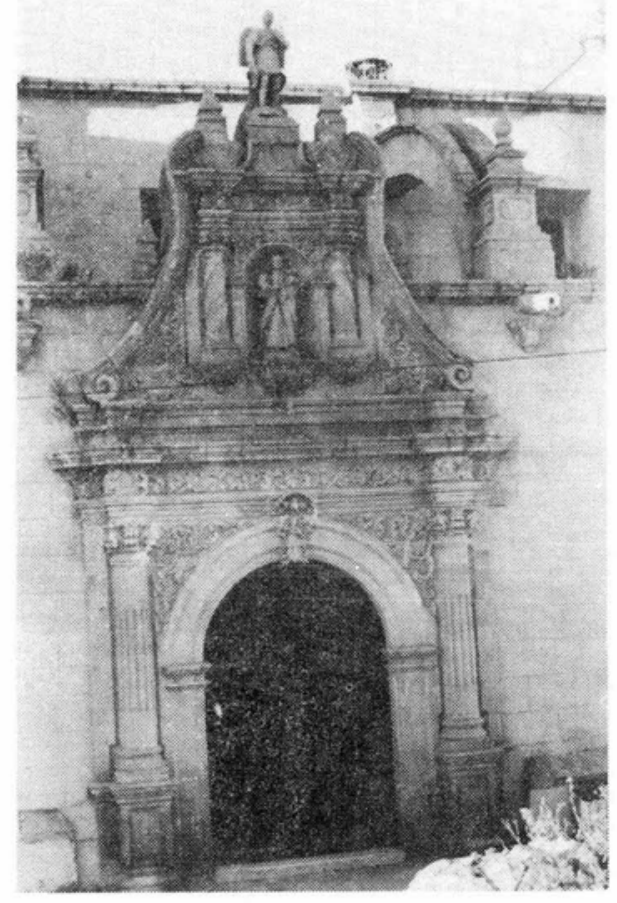

7. Parroquia de Santa Eulalia. Portada lateral.

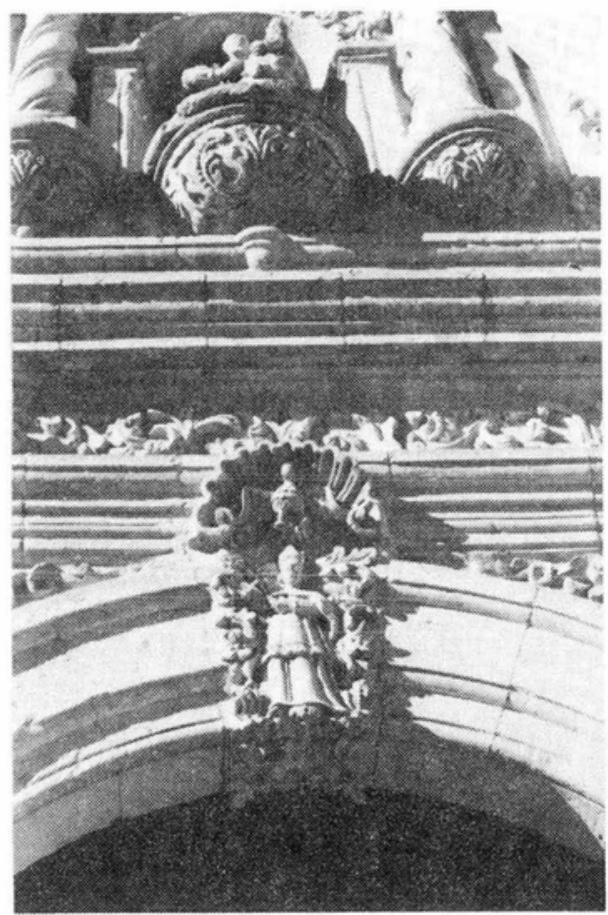

8. Parroquia de Santa Eulalia. Clave del arco de la portada lateral. 
DOI: http://dx.doi.org/10.22201/iie.18703062e.1989.60.1530

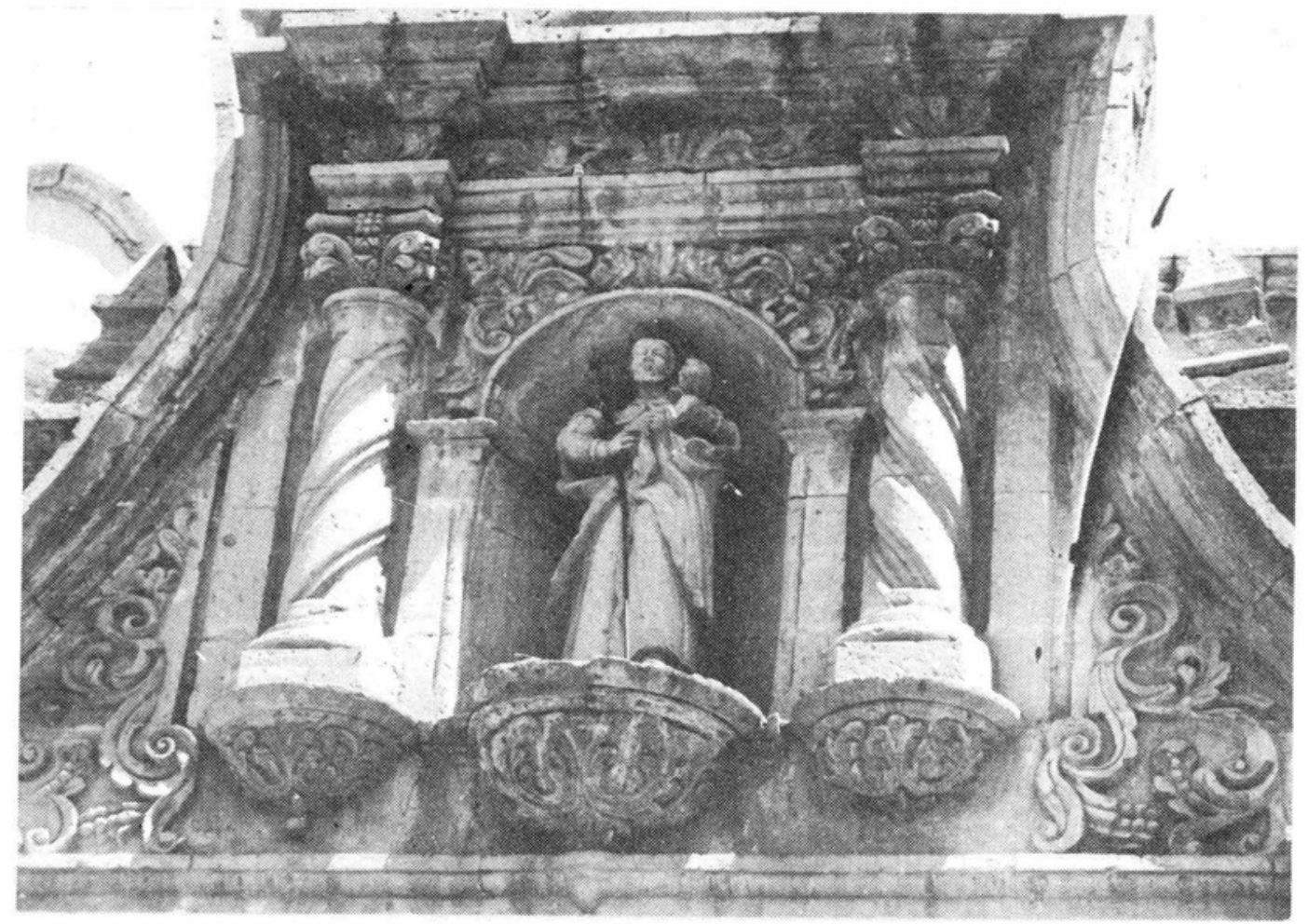

9. Parroquia de Santa Eulalia. Nicho del remate de la portada lateral.

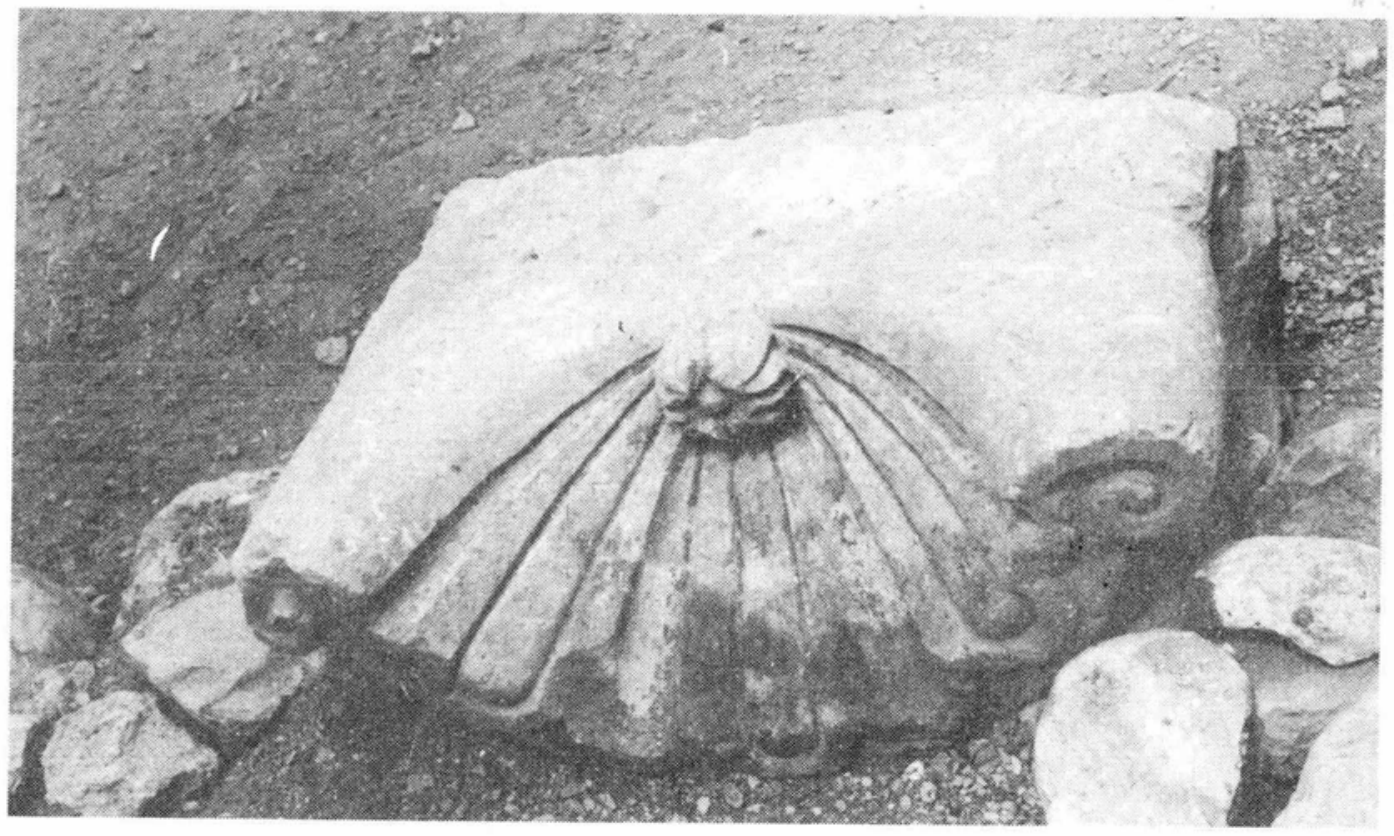

10. Parroquia de Santa Eulalia. Hornacina no utilizada. 
DOI: http://dx.doi.org/10.22201/iie.18703062e.1989.60.1530

11. Parroquia de Santa Eulalia. Retablo mayor.

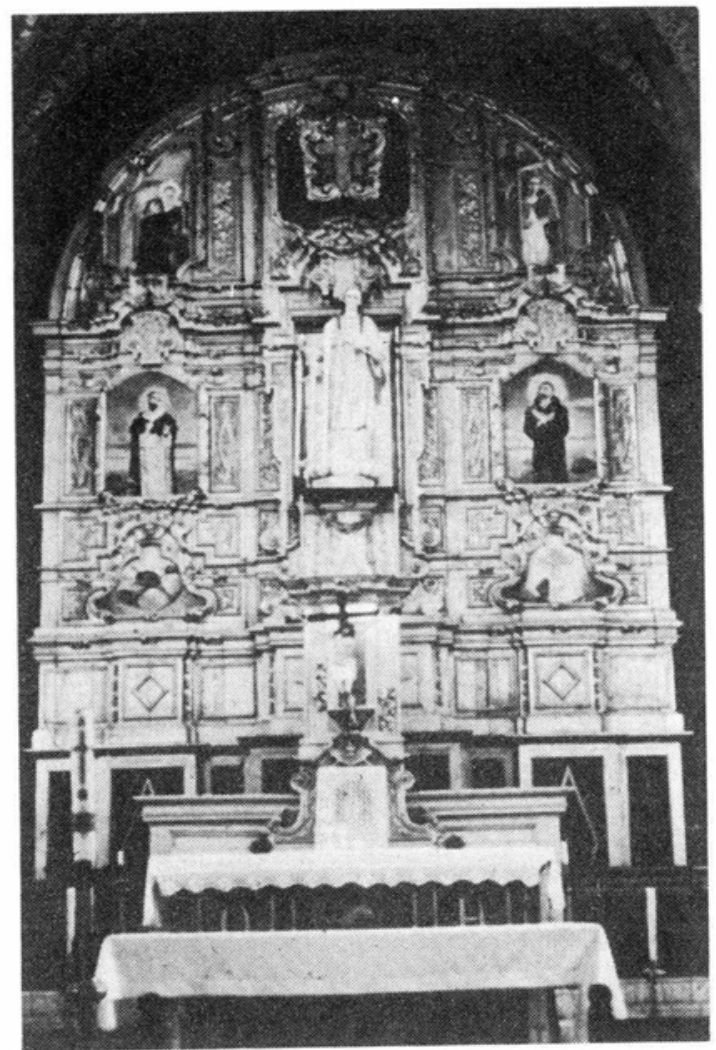

12. Parroquia de Santa Eulalia. Retablo del Santísimo.

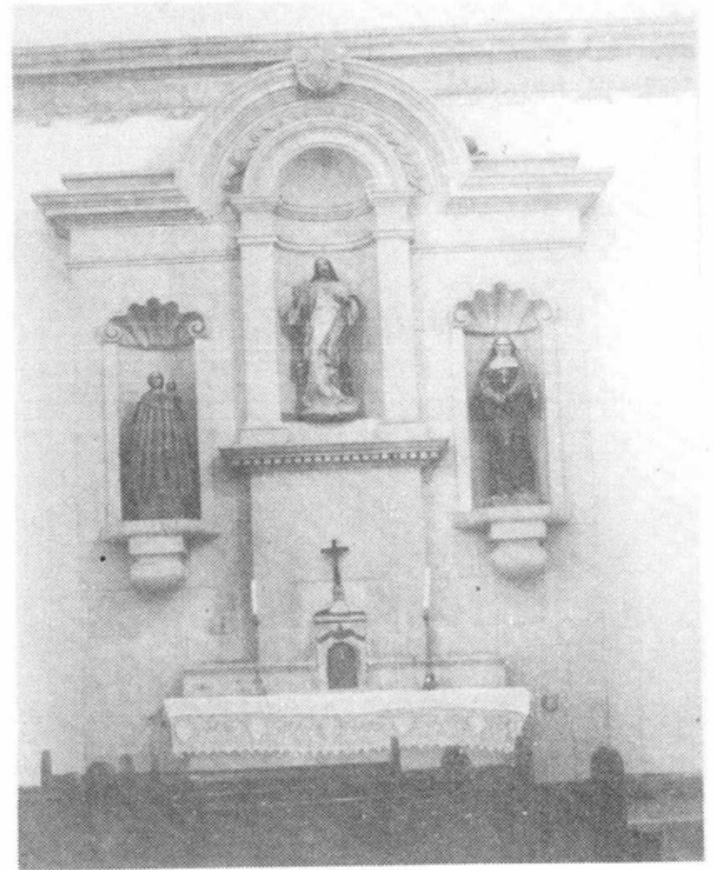


DOI: http://dx.doi.org/10.22201/iie.18703062e.1989.60.1530

13. Parroquia de Santa Eulalia. Retablo de la Virgen de Guadalupe.
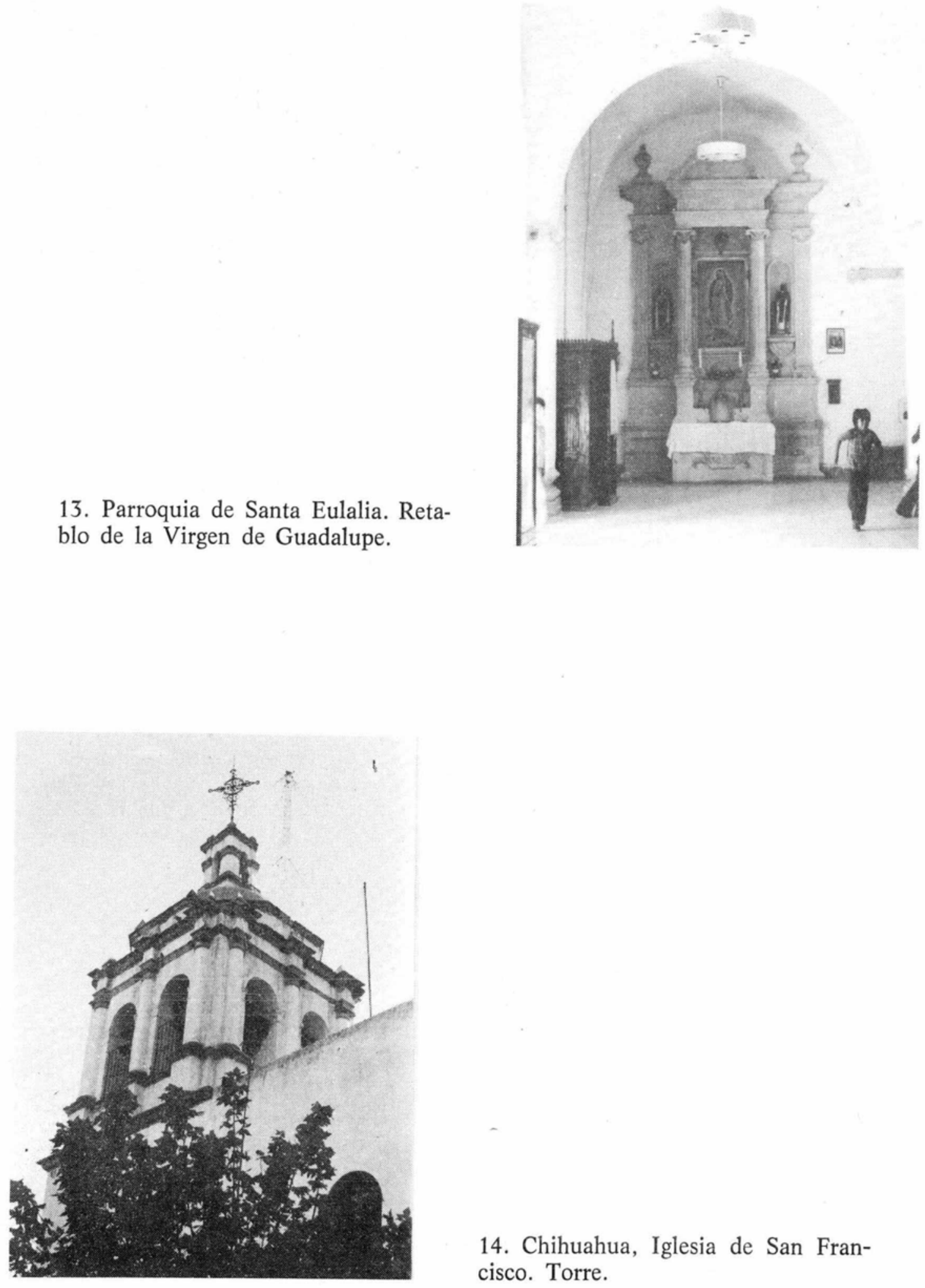

14. Chihuahua, Iglesia de San Francisco. Torre. 
executa y haze dicha Capilla determino su Ilma se pusiese en el altar mayor a el lado del evangelio dicha soberana Señora de la Mersed.

2. Extracto del inventario de la parroquia de Santa Eulalia, 17 de septiembre de 1760, ACD, Libro XXXV, ff. 181-182.

\section{En la iglesia}

Altar mayor. Un colateral grande de madera dorado con tres cuerpos. E1 primero tiene un nicho pequeño con tres vidrieras de cristal donde se halla la Soberana Imagen de Nuestra Señora de la Merced, mediana con un vestido de tela blanca en su peana de plata dorada y su corona y su Santísimo Niño con sus potencias. A los lados de dicha Señora se hallan dos santos de lienzo grande y dos chicos. Más arriba se halla la patrona Santa Eulalia de bulto grande. Tiene su parrila de plata y su paloma de plata. A los lados de dicha santa se hallan dos cuadros grandes. Más arriba se halla un San Antonio de bulto mediano y a los lados dos cuadros grandes.

El altar del Santísimo Sacramento y en él está colocada Nuestra Señora de los Dolores vestida y se halla Su Majestad depositado en su Sagrario de madera dorado. También hay un Santo Cristo grande y un cuadro que están en dicho altar.

Altar de Animas. Un cuadro con marco dorado.

Altar de Nuestra Señora de Guadalupe. Imagen de Nuestra Señora de lienzo grande con su marco dorado.

En la capilla se hallan tres altares. Uno con Jesús Nazareno con vestido morado. El segundo con el Señor San José de bulto grande. El tercero con San Fermín de lienzo y le adornan tres santos de lo mismo.

Altar del Rosario. Imagen de Nuestra Señora del Rosario de bulto grande vestida.

Altar de Nuestra Señora del Carmen vestida, en su colateral mediano, con tres santos de bulto y tres de lienzo.

3. Carta del Bachiller Pablo Francisco del Pozo, cura de San Felipe, al Dr. Pedro Anselmo Sánchez de Tagle, obispo de Durango. 25 de agosto de 1755.

En consequencia de lo que tengo noticiado a V. S. Ilma de los medios que diligenciaba este vecindario para la fábrica de su Yglecia, que tanto necesita; siendo el principal la cantidad que de los granos de la plata asignaron los mineros y vecinos de la Villa para esta Yglecia y su fábrica; pudo la solicitud y diligencia de Don Juan Joseph de Barrandegui, Theniente de Corregidor que es actual de este Real, conseguir el que los Diputados de la Real Aduana le entregasen este año ocho mil pesos .. quedando a entregar quanto antes puedan otros tres mil y tantos que restan de la supradicha asignación de los 
granos. Agregándose a esto lo que ha producido la carnicería de este Real en las dos onzas de carnero que de común $\mathrm{y}$ universal consentimiento se quitaron los vecinos destinándolas para este fin. $\mathrm{Y}$ así mismo el tener vistos a todos los mineros quienes ofrecieron un tenate diario de metal y los operarios concurrir también con lo que pudieren de sus partidos.

Estos ocho mil pesos recibidos luego que los traxo, Don Juan Joseph avisó privadamente a los más, sino fue a todos los vecinos, diciéndoles que su pensamiento era el embiar esta plata a México en el despacho para adelantar en ella viniendo de alla en reales al nueve o dies por ciento que produce este genero de remisions, pero para esto, siendo la plata de mala calidad, era necesario reducirla a buena, y así suplicó que los que pudiesen feriar algunas buenas lo hiziesen.

En este estado, llegándose ya el tiempo del despacho, en otra junta que el vecindario tuvo para otro fin, presentó Don Nicolás de Aragón un escrito pidiendo que leyese en aquella Junta; y siendo concerniente a esta plata de los granos, se difirió para otra Junta por citarme a mí para ella. Con efecto, en la siguiente se leyó el escrito en que pedía el pre... que respecto a que los ocho mil pesos de los granos era necesario al que se... tacen para que estos produ... con seguridad ofrecía el que si se los daban a censo, siendo esto por el mes de Junio, pagaría un dies por ciento obligándose a entregar principal y réditos de Agosto a Octubre del año venidero, dejando(?) también si se los daban docientos pesos para la fábrica de la presa del Agua, que fue el asumpto de la junta antecedente. Esto aseguraba obligando sus bienes, y después verbalmente ofreció fiadores.

Leido por principio de aquella junta este escrito, tomé la mano a decirles que como ya desde la primer Junta les avía propuesto, solo pertenecía a este vecindario en orden a la fábrica de la Yglecia y sus fondos el arbitrar y diligenciar los medios que fuesen más proporcionados; pero que el disponer y determinar en ella ni en sus fondos de ninguna manera pertenecía a otra que a V.S. Ilma y que assi lo que tenían que hazer era el arbitrar lo que fuese más conbeniente o proporcionado en uno o en otro medio de los que se eligiesen para que esto se propusiese a V.S. Ilma quien solo avía de determinar en la materia.

Para ... dixé que concideraba necessarios tres puntos sobre que se havía de discurrir y dar su parecer cada uno en aquella Junta. El primero: si no haviendo más fondo seguro que estos como doce mil pesos por lo contribuido de la Aduana, y producido del carnero, concideraban bastante para emprender Yglecia nueva que duraría mucho tiempo estando el mineral en la decadencia y escases en que se halla; o si fuera mexor (teniendo como tenemos tanta necesidad de Yglecia, así por su cortedad en que no cabe la gente, como por su indecensia y ruina que amenaza) el que ésta se repare o le diera extención y firmeza? A esto votaron los más por combeniente el que se diese extención y reparo a ésta, puesto que para ello eran suficientes los fondos; y casi todos combinieron en que bien sea para estención de ésta, bien para fábrica nueva, era combeniente el que se comense a trabaxar, para 
que a vista de esto se alentasen y esforsasen los ánimos, pues otras obras se han comensado con menos fondo.

A este parecer, propuso el supradicho Aragón el que se hisiese una dili. gencia y era el ver Maestros y prácticos que reconociendo el parage donde está la Yglecia viesen si havía capacidad para hazer en seguimiento de ella la que es Capilla Mayor y Presbiterio de otra nueba con su Crucero en la Capilla Mayor; y juntamente calculasen, si con los fondos que hai puede aver suficiente para fabricar lo dicho de cal y piedra, y de bóbeda. Que pudiéndose hazer esto si huviere más fondos se prosigue en la misma conformidad; y si no huviera, con romper la pared del Presbiterio de esta Yglecia vieja tiene ya toda esa extención, y con firmeza; y siempre nos queda en pie esta Yglecia sin que embarase a la fábrica nueva; ni ésta nos dexe sin Yglecia. Abrazóse generalmente este dictamen; y pasé a proponer el segundo punto.

Y fue: que en caso de que V.S. Ilma determinase que ésta vieja solo se reparase en lo que amenaza ruina que es el techo, y lo demas se reservase para hacerse Yglecia nueva en proporcionando más fondos, entonces era necesario que este dinero tuviese modo de producir y adelantarse. $Y$ para esto quál consideraban modo más a propósito, el de las remisiones de la plata a México o el de ponerse a censo como pedía el supradicho Aragón? Porque si en las remissiones a México, consideraban de incombeniente el riesgo que podía tener este dinero; no en la ida porque yendo en el despacho era riesgo remoto, sino en la venida de los reales, que vienen con un harriero particular; también en el censo se podía considerar alguna dificultad en su cobro al tiempo aunque estuviera con fiadores, como experimentamos muchas veses, y más estando la constitución presente de este mineral más para temer atrasos que para esperar adelantamientos en los mineros, como lo es el dicho Aragón, y pueden serlo sus fiadores. Que uno y otro medio se propusiese a V. S. Ilma para que eligiese el más combeniente en caso de ser nesesario. En esto hablaron confusamente, y me parece que más consintieron en el medio de ponerse a censo.

Propuse el tercer puntor: y es que determinando V. S. Ilma el que se comienze a trabajar en la obra, es nesesario el que aiga depositario de este dinero, y el que se adquiriere, Administrador uno o más, y éstos quien los havía de asignar y poner era V. S. Ilma. Y para esto no teniendo V. S. Ilma conosimiento práctico de los sugetos de aquí, se propusiesen dos o tres los que parecieren más a propósito para que de ellos elija V. S. Ilma si le pareciese o los que le pareciese. A esto dixo alguno, y otorgaron los demás, que mientras se hacía la diligencia de ver los maestros como arriba se dixo, y ver también, como entonces se propuso, a los mineros para que concurriesen, se suspendiese esto para otra Junta; acaso, según prudentemente juego con el conosimiento del estado de este negocio, porque entonces universalmente o casi todos huvieran votado por el dicho Don Juan Joseph Barrande. gui, como lo hizieron en la primera Junta para que diligenciase el cobro y percibiese este dinero.

En consequencia bajamos el dicho Theniente Don Juan Joseph y yo a la Villa, y vimos los mineros que, como dicho es, ofreciendo dar un tenate diario 
de metal. Vimos tambien el Maestro de Alarife que nos pareció mas proporcionado y en su compañía como práctico suplicamos que subiese el Br. Don Joseph Facundo. Y echo el reconocimiento, proporcionaron el poder salir la Yglecia en el paraje en que está, de sinquenta barras de largo dies de ancho, quedando detras de la Vieja que solo tiene treinta varas de largo, la Capilla Mayor de dies baras en cuadro con sus cruzeros como capillas de cinco baras cada una, y el Presbiterio de dies baras en quadro de bóbeda, y con su media naranja. Y que para esto especulando los gastos en las circunstancias de este paraje, puede haver bastante con lo que ai excistente, y lo que puede producir la contribución de los mineros, aun con la escazes de leyes en las minas.

Con esta especulación se hizo la otra Junta siendo dies y ocho sugetos los que se juntaron para votar las personas que se avían de proponer, nombrando cada uno tres personas; salieron con onze votos Don Pedro García de Villegas, con otros onze el supradicho Aragón; y con veinte el expresado Theniente Don Juan Joseph de Barrandegui. Se les propuso antes a todos por éste que qualquiera que huviese de correr con la obra no se avía de permitir que pagase en Xeneros ni cargase a los operarios o maestros, si no que semanariamente avía de pagar a todos en reales. Y con esto se quedó ya en que la consulta se hisiese a V. S. Ilma.

En ella expresando mi parecer por modo de informe a V. S. Ilma, digo que me pareze más combeniente el que la Yglecia se haga en la forma que se a especulado comenzando por el Presbiterio y Capilla Mayor a unirla con la Vieja. Y que para esto se comienze luego a trabajar en cimientos y prevenir materiales y hazer el rebaje que ha menester de un pedazo de Loma. Que ante todas cosas, se repare la Vieja en el hecho de Ormigón, porque lo tiene de tierra, y con qualquier Agua menuda nos vemos con mil trabajos porque toda se gotea.

Que si se elige Depositario y Administrador, de los nombrados sea uno porque dos no se han de llevar mui bien, y que este ponga su sobrestante, y cuidador de satisfación. Que el que fuere depositario dé fianzas del dinero que entrare en su poder por aora, y el que se adquiriere, llevando cuenta y dando recibos de lo que percibiere los que se entreguen al cura. Que se obligue el Administrador a que ha de pagar semanariamente en reales, y de otra suerte no se le pasará en quenta la que a de dar anualmente. Que entre los nombrados, sin poner algún defecto en los otros, me inclino a que sea Don Juan Joseph Barrandegui como que es a quien se deve el cobro de lo que ay, y por quien se facilitará lo que resta en la Aduana, y de otra suerte puede ser que se retarde. Este mi sentir, salvo siempre el mexor de V. S. Ilma, cuia determinación suplicamos rendidos en vista de la consulta que haze el dicho Theniente y éste mi informe para executar en todo lo que sirviese de ordenar y mandar V. S. Ilma, cuia importántisima vida en perfecta salud pido a Dios guarde.

Real de Santa Eulalia y Agosto 25 de 1755.

4. Carta de Juan José de Barrandagui al Dr. Pedro Anselmo Sánchez de Tagle, obispo de Durango. 25 de agosto de 1755. 


\section{Ilmo Señor,}

Juan Josseph de Barrandegui, vecino de el Real de Sta Eulalia de Mérida, y Chiguagua, su actual Theniente de Correxidor, en él, y Mayordomo de diez años a esta parte de la Fábrica de su Sta Yglesia, consulta a V.S. Ilma en cumplimiento de su obligación, con el mayor respecto devido, a la veneración que corresponde, a V.S. Ilma, el cstado presente en que se halla la Construción de la Fábrica Matherial de el Templo, que por este vezindario, a dias se ha intentado erixir, para la mayor deccencia culto y veneración de Dios Nuestro Sr., en cuyo exito, se han solicitado los medios mas congruentes, para la adquisición de los que se necessitan, para tan santa obra de que tanto se carece, assi por la deterioridad y decadencia de el que tenemos y ruina que amenaza, como por la poca cavida, por su estrechez, para cojer la Feligresia, y passando a relacionarlos digo, Sr., que aviendo sido movidos por mi los ánimos de los mineros y comerziantes de la Villa de Sn Phelipe y este Real, aya consignación de granos, para que parte de ellos se aplicasen a esta obra, se resolvió y acordó en Junta Gral, prosiguiesen por otros tres años, consignando su mitad para la perfección y conclusión a la Santa Yglesia de aquella Villa, y la otra mitad, sus dos partes para la de este Real, y la tercia de el para el Colegio de la Sagrada Compañía de Jesus de dicha Villa, y aviéndose conseguido la recaudación de onze mil y mas pessos, que en los tres años y sus despachos de ellos cupieron a este Real, se pusieron en mi poder los ocho, quedando los tres en la Real Aduana, que se entregarán despues por los Diputados, y aunque por mi parte, precediendo parezer de este Vecindario, se avía discurrido el medio de reducir la plata por ser de mala calidad a mejor y remitirla a Mexico a fin de interessarse un nueve o diez por ciento, traiendo los reales en beneficio y aumento de la Fábrica, se suspendió esta Dilixencia, con ocasión de averse perssonado dos o tres vezinos, pidiendo en Junta que se probocó, el que el Dinero que así se avia recaudado se diesse a Nicolas de Aragon, uno de los pretendientes, quien se obligava por el tiempo de diez y seis messes a dar un diez por ciento para coadyubar con esta utilidad a el aumento del principal, cuya propuesta no se admitió por los mas de los vezinos, haziendo repressentación de que con esta ocasión se retardava el dar principio a la obra que tanto se desseava, y que la que parecia mas conforme a este fin, era que luego y sin dilación se pussiese por obra la de la Fábrica, con cuya acción y a vista de esta determinación se exforzarian los Animos a coadyubar con limosnas y otros medios para su prosecución, pues con dichos onze mil pessos y como otros mil y mas que se han juntado de la suia de las dos onzas de Carnero, en cada real en este a que de comun conssentimiento de este vezindario se impusieron y estan corriendo, se consideraba por bastante peculio para principiar la obra, fuera de que se corrió por mi y el Br Don Pablo Francisco de el Pozo, cura coadjutor Viccario Juez Ecclesiastico de este Real, la previa Dilixencia de ver en persona a los Mineros de aquella Villa y este Real, a fin de moverles el animo para que concurriesen con un diario tenate de Metal en cada una de sus minas, lo que ofrecieron todos hazer con mucho gusto, dando orden como la dieron a sus Administradores para que assi lo hizieran de lo mejor 
que produjessen sus minas, y sin embargo de estar cortas a la pressente, no se duda será quantiosa la limosna que producirá, teniendo por Esperiencia que solo en una que se dedicaron a juntar en este modo un tanate de metal diario, produjo como setecientos pessos, con que se fabricaron tres Campanas que tuvieron de costa esta cantidad, poco mas o menos, a que se agrega la dilixencia que tambien corrimos en todas las minas con sus operarios y mandones, para que de sus pepenas ofreciesen semanariamente o diaria buena mente cada uno lo que quissiese dar, por ser en bien y beneficio de todos su destino, lo que of recieron ejecutar, y sin estos medios propuestos se advitraron otros al mismo intento, y assimismo se determinó por este vezindario el que la Fábrica de dicha Santa Yglesia se efectuase en el mismo lugar en donde esta, dejando esta en el medio prra el usso de los Santos Sacrificios. Todo lo qual, acordado de comun acuerdo, se passó a proponer a V.S. Ilma tres sugetos de este dicho Real para que de ellos se sirviese V.S. Ilma de nombrar de dichos tres, uno o dos de administradores, siendo los propuestos Nicolas de Aragon, Don Pedro Garcia de Villegas y yo, que hasta ahora ninguno esta aprobado, hasta dar cuenta, como llevo dicho, con todo lo demas relaccionado a V.S. Ilma para que su digna atencion en su vista, sea servido de determinar y resolver lo que fuera mas de su agrado, que sera como siempre lo mejor, cuya acertada providencia esperamos para dar principio a la obra. Nuestro Señor prospere y guarde la importantísima persona de V.S. Ilma muchos años en la mayor felicidad que le desseo.

Real de Sta Eulalia y Agosto veinte y cinco de mil setecientos cinquenta y cinco años. Ilmo Sr. Puesto a los pies de V.S. Ilma Juan Josseph de Barran. degui.

5. Auto del Dr. Pedro Anselmo Sánchez de Tagle, obispo de Durango. 17 de septiembre de 1755 .

En la Ciudad de Durango, a diez y seis dias de el Mes de Septiembre de mil setecientos cinquenta y cinco años, el Ilmo. Sr. Dr. Don Pedro Anselmo Sanchez de Tagle, Obispo de esta dicha Ciudad, Reino de la Nueva Vizcaya, de el Consejo de S. M.

\section{Mi Señor.}

Aviendo visto la preccedente Consulta, hecha por Don Juan Joseph Barrandegui como Iusticia Mayor de el R1 de Sta Eulalia de Merida, sobre nombrar depossitario de las cantidades que han producido los granos de cada marco de plata en aquel comercio y el de la Villa de San Phelipe de Chiguagua respectivamente, de lo que le cupo y perteneció de el repartimiento que de el todo se hizo; visto tambien las juntas celebradas por aquel vezindario de el citado Rl de Sta Eulalia, sobre empezar con dicha cantidad y las que produzgan o puedan ser avidas a construir una Yglesia en el, a caussa de estar la que tiene destruida, para cuya obra, deposito de las enunciadas cantidades y distribución de ellas, al mencionado fin se votaron tres sugetos, que son Don Pablo Garcia Villegas, Don Nicolas de Aragon, y el enunciado 
Theniente de Justicia Mayor Don Juan Joseph Barrandegui; visto finalmente los informes conque se halla su Ilma de las varias y eficazes dilixencias que ha hecho dicho Justicia Mayor para conseguir el aumento de Limosnas y recaudaziones de interesses para dicha Obra Matherial, con lo demas que fue nezessario y ... convino en la expressada conssulta conformes. Dijo su Ilma que ressidiendo en si como resside la facultad de declarar uno de los tres votados para depositario administrador y que corra con el cuidado de dicha obra Matherial que se intenta hazer, confiando como confiaba en la prudencia, madurez y celo de dicho Don Juan Joseph Barrandegui, y a mayor abundamiento las individuales noticias que tuvo el año de cinquenta y uno, estando en su vissita Dioccessana en aquel territorio, de su caudal, procederes y circunstanzias, lo declaraba y declaró por tal Depositario Admiristrador para dicha obra, dejando a los dos mencionados, Don Pablo Villegas y Don Nicolas de Aragon en su buen credito opinión y fama; Mandando asi mismo que dicho Don Juan Joseph Barrandegui sea tal Depositario Administrador vajo de las Calidades siguientes: La primera, que ha de dar fianza suficiente, buena, Lissa, llana y abonada de la Cantidad, o cantidades, que ayan entrado y entraren en su poder para la Construcción de dicha Fábrica, dando Noticia de ellas al que Ejerciese como Cura en aquel Rl. La segunda, que la Yglessia se aga en la forma que se a especulado y conferenciado y es empezarla por el Presbyterio y Capilla Mayor, a unirla con la existente, y que para esto se empiezen luego a trabajar los cimientos y prevenir los Matheriales conduccentes y necessarios, haziendo el rebaje que ha menester de un pedazo de Loma para su mejor asiento y planta. La tercera, que antes todas cosas se repare la existente de el Techo y suelo, pues segun su llma. tiene Noticia a poca que llueva, esta bastante humeda y con goteras. La quarta, que dicho Depositario Administrador ha de pagar semanariamente los Opperarios en reales, y no en otra especie, pues no siendo en reales no se le passara en cuenta en la que diere. La quinta, y ultima, que dicho Don Juan Joseph Barrandegui, como Depositario Administrador, recaude cobre y perciba, assi lo que estuviere pendiente y pertenezca a dicho destino, en la Rl Aduana de dicho Chiguagua, como otra qualquiera cossa que toque a la Construccion de dicha Yglessia. Todo lo qual mandaba su Ilma y mandó, observe, guarde, cumpla y ejecute, formando la Cuenta y razon correspondiente, en un libro forrado, con distinzión y claridad en sus partidas de recivo y gasto, y que se de cada un año al que como va dicho hiziesse ejercicio de Cura en dicho Rl, poniendo el que lo sea la aprovación o tachas que hallasse por convenientes y que de este Auto y la consulta que lo motiva se saquesse Testimonio a la Letra y remitasse a el Br Don Pablo Francisco de el Pozo, Cura Coadjutor de dicho Real, para que la aga notorio a sus vezinos. Su llma el Obispo mi $\mathrm{Sr}$ assi lo probeyó y mandó y firmó, de que doy fee. Pedro Ansselmo Obispo de Durango. Ante mi. Br. Carlos de Navia, Pro-secretario.

Concuerda este Thestimonio con la conssulta que se expressa y auto original a ella, providenciado que todo queda oy en esta secretaria de mi cargo, a lo que mie refiero, y para que conste donde convenga, doy el pressente de al 
superior mandado de su Ilma el Obispo mi Sr, que signé y firmé en esta Ciudad de Durango, a diez y siete dias de el mes de Septiembre de mil setecientos cincuenta y cinco años. En testimonio de verdad, lo firmé. Br. Carlos de Navia, Pro Secretario.

El cura, Pablo Francisco del Pozo, recibió este Auto el 1 de octubre de 1755 en Santa Eulalia y tomó providencias con el Teniente de Corregidor "que para el lunes siguiente a la semana de las fiestas (de San Francisco de Asís) que se hazen en la Villa, se sirva convocar y juntar a los vecinos para entonces hazerlo notorio". Asi sucedió el 13 de octubre en la casa del Teniente Barrandegui, presentes el cura, 19 vecinos y un notario. Ofreció de fiadores a Don Domingo del Valle y Don Pedro Antonio Cadrecha, vecinos del comercio de San Felipe. La fianza fue presentada el 19 de enero de 1756. Al final hay una nota que dice que se canceló la escritura de Barrandegui "por haberla pagado".

6. Presupuesto de Bernardo del Carpio para la parroquia y la presa de Santa Eulalia. 2 de marzo de 1758. (Los números entre paréntesis son correcciones mias.)

San Phelipe el Real y Marzo 2 de 1758 años

Regulación de los mapas de la Vuelta para la Yglesia del Real de Santa Eulalia. Es a saber:

1,162 Varas cúbicas de Cal y Canto que Se ynclullen en 15 traspilares y para ello son menester 4,648 cargas de piedra a 2 reales ........

600 Fanegas de Cal a 7 reales ............. 525 pesos

1,200 Cargas de arena a 2 reales ........... 300 pesos por mesclar dicha Cal y arena ......... 76 pesos de operarios para lebantar los dichos pilares en 24 dias de trabajo 672 pesos

2,330 Cuñas para las esquinas de los pilares a 5 pesos (el cien) por su saca ......................... 116 pesos 4 reales por su flete a 5 pesos el siento .......... 116 pesos 4 reales por labrarlas a 4 pesos el siento ........ 93 pesos

60 Piedras de medida para las Repisas a 4 reales 30 pesos por su flete a 2 reales .............. 15 pesos por labrar las dichas a 2 pesos ........ 120 pesos

616 Varas cúbicas de Cal y Canto que asen las paredes del presviterio, Crucero y Sachristia asta 4 varas de alto, les entran 2,464 Cargas de piedra que a 2 reales valen ........... 616 pesos

308 Fanegas de Cal a 7 reales ............. 269 pesos 4 reales

616 Cargas de arena a 2 reales .............. 154 pesos

por mesclar dicha cal .............. 45 pesos por 25 dias de trabajo de operarios ...... 700 pesos 
845 Varas cúbicas de piedra y lodo a las que le entran 1,380 cargas de piedra a 2 reales 345 pesos por lebantar dichas basas de paso (?) en 36 dias de trabajo 1,008 pesos

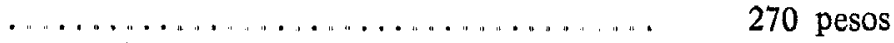
por su flete a 5 pesos el siento ........... 270 pesos por labrar las dichas a 4 pesos el siento... 232 pesos ( 216 p.) por asentar los 8 arcos del Cuerpo de la yglesia en 32 dias de trabajo con 4 oficiales con su jente ............. 1,040 pesos

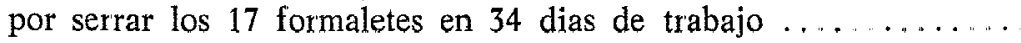
1,105 pesos

8,000 Cuñas para serrar las 8 bobedas del Cuerpo de la Yglesia por su saca, flete y labrado ................... 1,120 pesos por serrar las bobedas a 120 pesos cada una asen 960 pesos

236 Varas cúbicas de Cal y Canto que conponen los pretiles de la Yglesia, le entra 942 Cargas de piedra a dos reales 223 pesos (235 p.

118 Fanegas de Cal a 7 reales ............. 103 pesos 2 reales

436 Cargas de arena a 2 reales ............... 109 pesos de oficiales y operarios en 9 dias de trabajo, 4 oficiales ............ $\ldots \ldots \ldots \ldots \ldots \ldots \ldots \ldots \ldots \ldots . \ldots \ldots . \ldots \ldots 2$ pesos por mesclar dicha Cal y arena....... 18 pesos

424 Varas cúbicas que conponen el Cubo de la torre, le entran 1,884 Cargas de piedra a 2 reales 424 pesos $(471 \mathrm{p}$.

300 Fanegas de Cal a 7 reales .............. 262 pesos

600 Cargas de arena a 2 reales ............. 150 pesos por mesclar dicha Cal y arena ......... 45 pesos de operarios y oficiales en 17 dias de trabajo, 4 oficiales 476 pesos

54 Escalones para el Caracol a 2 pesos por su saca, flete y labrado. 108 pesos

162 Cuñas para las esquinas del Cubo por su flete y labrado

22 pesos 6 reales por el anillo del Simborrio con 24 varas de alquitrabe, 24 de friso y 24 de cornisa a 10 reales el alquitrabe, a 1 peso el friso, a 2 pesos la cornisa . .................... 102 pesos

72 Piedras de medida para dicho anillo, por su saca y flete ........ .............................. 54 pesos por el simborrio de material y manifactura con su Lanternilla y 4 bentanas 1,856 pesos por 13 canales maestros ............. 52 pesos por 2 puertas de los Costados a 150 pesos por la piedra, flete y labrado 300 pesos 
por 4 puertas para la Sachristia de Cuña por su saca, flete y labrado a 30 pesos ................... 120 pesos

800 Fanegas de Cal para los enjarres y reboques a 7 reales .......... ............................ 700 pesos

por los enjarres y reboques .......... 600 pesos por abrir y ... los simientos y su material 1,500 pesos

300 Cuñas para los Capialzados de saca, flete y labrado por 8 bentanas de Cuña por su saca, flete y labrado

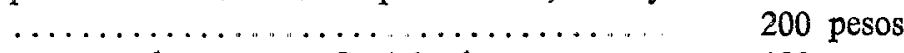

por ponerlas con sus Capialzados ........ 120 pesos

para maderas tarcia para andamios y artes de la obra ....

1,800 pesos

150 Varas cúbicas de Cal y Canto que Conpone la frente de la Yglesia en los que entran 600 cargas de piedra a 2 reales valen ..........

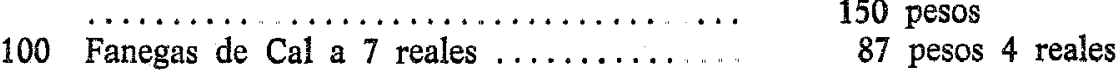

por 200 cargas de arena a 2 reales ........ 25 pesos $(50$ p.)

por lebantarlas en 12 dias de trabajo ..... 336 pesos

por la portada principal de piedra, su saca, flete y labrado

836 pesos

por la torre con Cornisas, basamento y ynpostas de Canteria y lo demas de Cuña labrada de un Cuerpo como el mapa demuestra echa su exctroctura tendrá de costo ........... 2,043 pesos

por 60 bigas para la Sachristia y ante Sachristia a 5 pesos

........................... 300 pesos

por labrar las dichas a 10 reales ........ 75 pesos

por 3,000 tabletas a 8 pesos (el millar) ... 24 pesos

por el trabajo del director o Maestro considerado bien esta obra puede durar el tiempo de dos años y cada uno 300 dias a Razon de 4 pesos montan

2,400 pesos

27,415 pesos 4 reales $(27,388$ p. 4 r. $)$

Regulación de la presa que se pretende aser en el Real de Santa Eulalia. Es a saber:

749 Varas cúbicas de Cal y Canto les entran 5,992 cargas de piedra de monte a 1 real cada carga . . . . . . . ..... 949 pesos $(749$ p.)

1,000 Fanegas de Cal a 7 reales ............. 875 pesos

2,000 Cargas de arena a 2 reales ........... 500 pesos

366 Cuñas para las esquinas de los pilares por su saca, flete y labrado a 14 pesos el siento ................. 51 pesos

24 Piedras de medida para la Compuerta, por su saca, flete y labrado a 4 reales la saca, a 4 el flete y su labrado a 2 pesos ynporta

96 pesos 
de operarios y maestro y sobrestante en 124 dias de trabajo, con 2 oficiales y 14 peones ................ 1,736 pesos Madera para andamios me ago cargo que en dicho Real no faltará quien preste.

por mesclar la Cal y arena

150 pesos

por abrir los Simientos

360 pesos

4,717 pesos

$(4,517$ p.)

Estas son las Cantidades salbo yerro por que se pueden aser dichas obras dando el agua franca o en la presa echa o en los posos ynmediatos.

Bernardo del Carpio 